\title{
Internet Addiction, Emotional Intelligence and Anxiety in Youth
}

\author{
Ms. Rashi Juneja ${ }^{1 *}$, Ms. Smriti R. Sethi ${ }^{2}$
}

\section{ABSTRACT}

With Informational Technological advancement, everyday new media is increasing the percentage of Internet addicts which appears as a potential problem in youth. Internet addiction according to DSM-5 is being observed as predominant problems in today's youth. Research findings have proven that there exists a fine line between the time wherein we regulate technology and the time technology begins to govern our lives. Of the several voids that an individual encounters during the course of life is that of anxiety. At the time of it's inception the internet had been confined to certain specific uses but with the passage of time it has reached a stage wherein the dependence of the individual has increased to an extent that it has become an obsession. Having said that, a brief explanation is required to support the statement put forward. When the individual under review shares a piece of information on the internet the thought process doesn't end once the sharing is done, instead the notion of the circulation of the information tends to play on the mind of the individual making the person uneasy and anxious in terms of thought process. Moreover, a relationship exists between emotional intelligence and internet addiction assuming an internet addict to be low on emotional intelligence The present research has been undertaken to study the relationship between internet addiction, emotional intelligence and anxiety level of youth The study will be conducted on 50 males and 50 females (studying in colleges from Delhi and NCR), will be tested on Internet Addiction Test (by Dr.Kimberly Young), Hamilton Anxiety Rating Scale (HAM-A, . Br J Med Psychol 1959) and Emotional Intelligence Scale (Schutte, N. S., Malouff, J. M., Hall, L. E., Haggerty, D. J., Cooper, J. T., Golden, C. J., \& Dornheim, L. ,1998). For this purpose, an appropriate statistical tool was used to analyze the relevant primary /secondary data Detailed results will be discussed in the full paper. It seems that internet usage is a boon for the society but may also prove to be a bane unless we focus on its positive, productive and controlling practices to manifest and promote its usage in the positive way for nurturing of values, ethics, personality, their psychological wellbeing and healthy lifestyle of youth themselves and their society.

Keywords: Internet addiction, Emotional Intelligence and Anxiety.

Lately much of the researches have been documented in respect to the problem of internet addiction among adolescents. This issue is quiet problematic nowadays because internet provides a constant source of information and entertainment and can be easily excess from anywhere in

\footnotetext{
${ }^{1}$ Student, M.Phil. Clinical Psychology, Amity Institute of Behavioral, Health and Allied Sciences, AUUP

${ }^{2}$ Assistant Professor, Amity Institute of Psychology and Allied Sciences, AUUP

*Corresponding Author

(C) 2015 I R Juneja, S Sethi; licensee IJIP. This is an Open Access Research distributed under the terms of the Creative Commons Attribution License (http://creativecommons.org/licenses/by/2.0), which permits unrestricted use, distribution, and reproduction in any Medium, provided the original work is properly cited.
} 
the world. Social networks, email, blogs, instant messaging, and message boards allow for both public and anonymous communication about any topic. But the question arises, how much is too much Internet usage? Many of the adolescents turn to the Internet, especially to social networking sites in order to manage unpleasant feelings such as loneliness, stress, depression and anxiety. When an individual have a bad day and wants to look for a way to take a flight away from the problems or to take a quick relieve from stress through the Internet. Losing oneself online can temporarily make an individual's feelings of stress, loneliness, anxiety, boredom and depression evaporate into virtual reality.

Now the notion of addictive behavior is ayont the initial definition. Results of various researches of this phenomenon caused expansion of both scientific interest of researcher and approach to dependent behavior definition. Those, who are under the influence of irresistible need for object, substance, action or interaction, the imagination or an environment which is a source of psychophysiological "pleasure". The condition of "pleasure" works as the mechanism of a copying giving pleasure with any mental or physical tension, a stress or pain or the conflict (Babayeva et al., 200).

Now more of a intrapersonal factors, i.e. personal features which define susceptibility to addiction formation are studied. Modern researchers hold the opinion that, despite existence of the certain personal features contributing to formation of dependence the addiction as a personality trait doesn't exist. But number of researches of personal traits among addictive persons showed that negative qualities, such as tendency to blame others for everything, falsity, insatiability, exaggeration of the advantages, irresponsibility etc. can provoke process of dependent behavior. All bethink factors that may lead to the formation and development of addictive behavior are most brightly shown when dependence is formed at teen age . As the main reasons for formation of an addiction among teenagers Rudakov I.A. allocates: self-affirmation, family relationships, positive advertising in mass media, an unemployment of free time, psychological features of the personality, absence of knowledge addiction consequence, influence of public culture, avoiding any problem (Rudakova, 2005).

It is equally important and also interesting to mention that some people are surely hurting themselves by their addiction to cyberspace. When people lose their fail out of school, lose their jobs or are divorced by their spouses because they cannot oppose devoting all their time to virtual lands, they are addicted pathologically. But in all sought of addictions, the problem is where one need to draw the line between "normal" enthusiasm and "abnormal" preoccupation.

People mostly become "addicted" to the internet when they have dissociated from their true life. That is the time when cyberspace activity becomes a world in itself and takes over the reality. It becomes a substitute or an escape from their life. Cyberspace almost becomes a dissociated part of their own mind - a sealed-off intrapsychic zone where fantasies and conflicts are acted out. 
Fixing this dissociation is an implicit or explicit component of many of the techniques for helping internet addicted people.

Most of the researches regarding emotional stability, emotions and emotional intelligence showed that the people in cyberspace can take much more emotional saturation than in their real surrounding. Golman (1998) had define Emotional Intelligence (EI) as an array of skills and characteristics that drive leadership performance. According to him EI includes five major components which are Self-awareness, Self-regulation, Social skills, Empathy and Motivation. In a study by Hasan Khoshakhlagh and Salar Faramarzi (2011) on the Relationship of Emotional Intelligence and Mental Disorders with Internet Addiction in Internet Users University Students. Results showed that emotional intelligence have been the best predictors of Internet addiction and there is a significant relationship among emotional intelligence, internet addiction and , mental disorders (Khoshakhlagh, 2014). Emotional intelligence is the ability to recognize one's own and other's emotions as well as emotional regulation (Saloway, Mayer).

Peele (1991) explained the psychological addiction as "it gives an individual the feelings and gratifying sensations that one is not able to get in other ways. It may block out sensations of uncertainly, pain or discomfort. It may enable a person to forget or feel "okay" about some insurmountable situations or problems. It may provide a temporary feeling of calm, of security, of accomplishment, of self worth of power and control, or intimacy or belonging." It is these perceived benefits which can explain the 'why' of the person keeps bouncing back to the addictive experience.

\section{REVIEW OF LITERATURE}

Internet addiction disorder (IAD), now more commonly called problematic Internet use (PIU) or compulsive Internet use (CIU). Other overlapping terms include Internet overuse, problematic computer use or pathological computer use - and even iDisorder. Internet addiction is characterized by excessive and uncontrolled preoccupations regarding Internet use which may lead to distress. The number of internet users in Iran has been increased more than $3100 \%$ between the years 2000-2006 and this figure is now more than 11.5 million people. According to the research, the highest number of internet users is the youth. According to a research done by Fallah Mane (2008), internet addiction is defined as the disorder resulting from unreasonable and pathological use of internet. This phenomenon is also known as virtual addiction. Internet addiction includes being addicted to chat rooms and pornography and may also lead to the degradation of the individual's mental health and feelings.

Emotional intelligence is the ability to recognize one's own emotions and of others. It also includes emotion regulation in social situations (Kezwara \&Boloke: 2009) that tries to explain and interpret the position of emotions in human capabilities so that individuals are reached to self-awareness-based self-control (Kahef Elahi and Doostar, 2003). Emotional intelligence also 
refers to true understanding of the self-motivation, environment, recognition and controlling of one's own feeling \& those of others (Salovey and Mayer).

In a study done on 332 students at schools in California regarding the relationship between impulsiveness, personality traits and addiction by Merkerk, Ajenden and Franken (2010) showed that internet addiction can be one of the predictors of impulsivity and anxiety. The results of the study has showed that there is a significant relationship between the internet addiction and mental health.

In a review regarding the relationship between internet addiction with emotional intelligence over 209 adolescents, age 13-15 years old and 458 youths age 16-18 years, by Parker, Taylor and Laura Wed (2008) concluded that emotional intelligence in each age can be a good prediction of the rate of internet addiction. Emotional intelligence can predict internet addiction of $76 \%$ and $56 \%$ at the age range of $16-18$ years.

In a study by Henderson, Hinisi and Martin (2006) regarding the factors that may cause internet addiction among various university students, reckoned that factors such as low social support, masculinity and neurotic personality trait can be the predictors for internet addiction.

People who are seen to be addicted to internet face a lot of physical side effects back strain, eye strain, like sleep disturbance etc. Such people may also experiences academic, family and social problems (ASAM, 2012). Among the worst affect of internet addiction is anxiety, depression and stress. Increase in the use internet makes some problems and one of them is internet anxiety (Nima, 2012). There exists a positive and significant correlation between the level of anxiety and internet addiction (Nima, 2012). Problematic internet usage may lead to avoidance to face the social interactions and worsen social fears (Lee \& Stapinski, 2012). There is also found a significant relationship between anxiety and depression in childhood with internet addiction in adolescent. Clinicians should consider anxiety during childhood to prevent internet addiction (Cho \& shin, 2013). Thus the study shows that anxiety significantly predicts internet addiction.

Another factor is that of gender difference. The preponderance of internet addiction in male students is more than female students (Jalalinejad, 2012). Internet addiction also effects social relation. It makes people more introvert and away from family and society (Cardak, 2009). Social networking can be potentially harmful to the people (Evgeny, 2009).

\section{METHODOLOGY}

\section{Aim of the Study}

To assess internet addiction, emotional intelligence and anxiety among youth.

\section{Objectives}

- To understand signs and symptoms of internet addiction in youth.

- To study the relationship between of emotional intelligence internet addiction in youth.

- To study the relationship between anxiety and internet addiction in youth. 
- To study the difference in the level of internet addiction, emotional intelligence and anxiety among males and females.

\section{Hypothesis}

- There will be no significant difference in Internet addiction, emotional intelligence and anxiety among boys and girls.

- This will be no correlation between internet addiction and emotional intelligence \& Internet addiction and anxiety among the boys and girls

- Girls will be higher on anxiety than boys with internet addiction.

- Girls will be higher on emotional intelligence than boys with internet addiction

\section{Sample and Research Design}

- Total of $500(\mathrm{~N}=500)$ youth were taken as sample (250 boys and 250 girls) .

- Age $18 y r s$ to 24 yrs.

\section{Inclusion Criteria}

500 Boys and Girls from colleges of Delhi and NCR were administered Internet Addiction Test and only the ones who scored high were administered further on Emotional Intelligence and Anxiety

\section{Statistics}

Mean, Standard Deviation, correlation and t-test are used.

\section{RESULTS AND DISCUSSION}

\begin{tabular}{|c|c|c|c|c|c|c|}
\hline \multirow[t]{2}{*}{ VARIABLES } & \multicolumn{2}{|c|}{$\overline{\text { IAT }}$} & \multicolumn{2}{|c|}{ HAM-A } & \multicolumn{2}{|c|}{ EIS } \\
\hline & BOYS & GIRLS & BOYS & GIRLS & BOYS & GIRLS \\
\hline MEAN & 90.91 & 83.89 & 41.10 & 50.22 & 39.06 & 45.18 \\
\hline STANDARD DEV & 2.48 & 4.92 & 8.30 & 9.07 & 2.45 & 6.24 \\
\hline
\end{tabular}

\begin{tabular}{|lc|}
\hline CORRELATION BETWEEN EIS \& IAT \\
\hline Boys & $-0.875 * *$ \\
\hline Girls & $-0.791 * *$ \\
& $* \mathbf{p}<.05, * * \mathbf{p}<.01$
\end{tabular}




\begin{tabular}{|lc|}
\hline CORRELATION BETWEEN EIS \& HAM-A \\
\hline Boys & $0.231 * *$ \\
\hline Girls & $0.241 * *$ \\
\hline & $* \mathbf{p}<.05, * * \mathbf{p}<.01$
\end{tabular}

\begin{tabular}{|lc|}
\hline T Test \\
\hline IAT (BOYS \& GIRLS) & 0.39 \\
\hline HAM-A (BOYS \& GIRLS) & 1.36 \\
\hline \multirow{2}{*}{$\mathbf{p}<.05, * * \mathbf{p}<.01$} \\
\end{tabular}

\section{DISCUSSION AND CONCLUSION}

"Anxiety is practicing failure in advance"- seth godin. Very aptly put into words that anxiety never satisfies your fears but it aggravates them to a different level. Same is the result indication of young adults being more prone to internet addiction and experiencing a higher level of anxiety for day to day life schedule especially in girls. Females by nature are more inquisitive and far sighted than males which make them think more on any issue and thus can give rise to anxiety in varied situations. On the top of it internet addiction is supporting their anxiety levels as it hinders their sleep process and adds to stress in personal and professional life; vice versa males do not experience the same level of anxiety. They score lower in emotional intelligence than females. Emotional intelligence is the ability to create a balance between knowing what you don't know and that what you do know can be improved. It is definitely a mammoth task for young males to get into self analysis of such kind and balance out emotions so definitely girls tend to have an edge over such issues because of their intense thought process and planning ahead in life.

Boys are more addicted to internet than girls as girls will further have some distractions of gossiping with friends or just shopping around but boys are more prone to sitting on the internet for some or the other reason. They are not only using it for study or jobs but do fall prey to online gambling and other such processes.

According to a study published in this month's issue of General Hospital Psychiatry, excessive use of the Internet can cause Internet Addiction Disorder, or IAD, which can lead to anxiety and depression. "Something becomes an addiction when it becomes problematic, when you choose to continue to do something in spite of consistently negative consequences," said Bill Arck, director of K-State's Alcohol and Other Drug Education Service. The concept of IAD was introduced in 1995 by researcher Ivan Goldberg, according to the study. Since then, there have been a variety of definitions of excessive Internet usage, including compulsive computer use, Internet addiction. 
The study, authored by Frederico Tonioni entitled "Internet addiction: hours spent online, behaviours and psychological symptoms," defines an essential criteria to diagnose IAD as "a misuse of Internet, characterized by many hours spent online avoiding interpersonal relationships with real or known person.”

An individual is at a greater risk of Internet addiction if person suffer from anxiety that is the person uses internet to distract oneself from your worries and fears. Anxiety disorder like obsessive-compulsive disorder may also contribute to an excessive checking of emails and compulsive use of internet, one may be depressed and at that time internet can be an escape from feelings of depression, stress, isolation and loneliness or to get social support from virtual world which is missing in real world.

Signs and symptoms of Internet addiction varies from person to person. For example, there are no set numbers of hours per day which indicate Internet addiction. But here are some general warning signs that may show that internet use may have become a problem. This may include losing track of time while being online, having trouble completing tasks at home or work, isolation from family and friends, Feelings of having a sense of euphoria while involved in Internet activities and feeling guilty or defensive about your Internet use.

Internet addiction can also lead to physical discomforts like dry eyes or strained vision, carpal tunnel syndrome (pain and numbness in hands and wrists), sleep disturbances, pronounced weight loss or weight gain and neck aches and back aches and severe headaches.

When used responsibly, the Internet can be a great place to interact socially, meet new people, and even start romantic relationships. However, online relationships can often be more intense than those in real life. Our fantasies are given free reign and the idea of being with our online love can exceed all realistic expectations. Since few real-life relationships can compete with these wild, fantasy relationships, the Internet addict will prefer to spend more and more time with their online friends. Another problem is that about $50 \%$ of people online lie about their age, weight, job, marital status, or gender. When online friends meet and the real-life person fails to match the online persona, it can create profound emotional disappointment.

Therapy can give you a tremendous boost in controlling Internet use. Cognitive-behavioral therapy provides step-by-step ways to stop compulsive Internet behaviors and change your perceptions regarding Internet and computer use. Therapy can also help you learn healthier ways of coping with uncomfortable emotions, such as stress, anxiety, or depression. If your Internet use is affecting your partner directly, as with excessive cybersex or online affairs, marriage counseling can help you work through these challenging issues. Marriage counseling can also help you reconnect with your partner if you have been using the Internet for most of your social needs the Be a good role model \& Manage the Internet and computer use in your own life well, Introduce the Internet addict to other people who handle their Internet use sensibly. Talk to your 
friend about your concerns with their Internet use, Support their desire for change if they think they have a problem or Encourage them to seek professional counseling.

There are a number of steps that one can take to get the internet use under control. The steps that an individual can initiate himself or herself can be to recognize any underlying problems that may support the internet addiction. If you are struggling with anxiety, depression and stress for example, Internet addiction might be a way to self-soothe rocky moods.

Build coping skills because at times blowing off steam on the internet is the way of coping with angry feelings and stress. Or maybe one have troubles in relating to others or are excessively shy with people in real life. Building skills in these areas will help the individual weather the stresses and strains of daily life without resorting to compulsive Internet use.

Strengthen your support network because the more relationships a person have in real life, the less you will need the Internet for socializing and interaction. Each week take out time for friends and family. If you are shy, try finding common interest groups such as a sports team, education class, or book reading club. This allows you to interact with others and let relationships develop naturally.

It's a fine line as a parent. One severely limit a child or teen's Internet use, they might rebel and go to excess. But as a parent one should monitor computer usage, supervise online activity, and get the child help if he or she needs it. If the child or teen is showing signs of Internet addiction, there are things that a parent can do to help like Encourage other interests and social activities, Monitor computer use and set clear limits, Talk to your child about underlying issues (help the child in expressing his/her emotions ) etc.

\section{REFERENCES}

Esterling BA, L’Abate L, Murray EJ, Pennebaker JW (1999) Empirical foundations for writing in prevention and psychotherapy: Mental and physical health outcomes.

Griffiths, D. (n.d.). AN OVERVIEW OF ONLINE ADDICTIONS. Lecture presented in Nottingham Trent University.

İSKENDER, M., \& AKIN, A. (2012). SELF-COMPASSION AND INTERNET ADDICTION. The Turkish Online Journal of Educational Technology, 10(3).

Jafari N, fatehizade M. Prediction of Internet Addiction,Based on emotional intelligence Among Isfahan University Students. 3. 2011; 12 (45) :79-86

Jalaleddin, H., Mohadese, B., Mehdi, H., \& Fatemeh, B. (2013). The Relationship between Emotional Intelligence and Technology Addiction among University Students. International Journal of Collaborative Research on Internal Medi, 5(5), 310-310.

Khoshakhlagh, H. (n.d.). The Relationship between Emotional Intelligence and Mental Disorders with Internet Addiction in Internet Users University Students | Khoshakhlagh | Addiction and Health. 
Khoshakhlagh, H., \& Faramarzi, S. (2012). The Relationship of Emotional Intelligence and Mental Disorders with Internet Addiction in Internet Users University Students. Addict Health, 4(3-4).

Khoshnazar, E., Zokaie, E., Ranjbardar, S., \& Kermani, F. (2014). RELATIONSHIP BETWEEN ATTACHMENT STYLES AND EMOTIONAL INTELLIGENCE WITH PROBLEMATIC INTERNET USE. Indian Journal of Fundamental and Applied Life Sciences, 2014 Vol. 4 (S4).

Mesgarani, M., Shafiee, S., Ahmadi, E., \& Zare, F. (2013). Studying the Relationship between Internet Addiction and Emotional Intelligence, Sensation Seeking and Metacognition among those Who Referred to Cafes. International Research Journal of Applied and Basic Sciences, 4 (4)(2251-838X), 889-893.

Oktuğ, Z. (n.d.). Gender Differences in Internet Addiction and Tendency to Express Emotions.

Singh, G. (n.d.). High internet use is related to low emotional intelligence. Retrieved October 30, 2015.

Vesile, O. (n.d.). The Predictive Relationship between Emotion Management Skills and Internet Addiction. Social Behavior and Personality. 